\title{
On-Chip Antenna Design Using the Concepts of Metamaterial and SIW Principles Applicable to Terahertz Integrated Circuits Operating over 0.6-0.622 THz
}

\author{
Ayman A. Althuwayb \\ Electrical Engineering Department, Jouf University, Sakaka, Aljouf 72388, Saudi Arabia \\ Correspondence should be addressed to Ayman A. Althuwayb; aaalthuwayb@ju.edu.sa
}

Received 28 October 2020; Revised 10 November 2020; Accepted 22 November 2020; Published 8 December 2020

Academic Editor: Diego Caratelli

Copyright (c) 2020 Ayman A. Althuwayb. This is an open access article distributed under the Creative Commons Attribution License, which permits unrestricted use, distribution, and reproduction in any medium, provided the original work is properly cited.

\begin{abstract}
This research work presents the investigation of realizing an on-chip antenna based on the metamaterial concept, which is working over the terahertz $(\mathrm{THz})$ band for applications in integrated circuits. The proposed on-chip antenna is constructed of five stacked layers of polyimide and aluminum as top and bottom substrates, radiation patches, ground plane, and feed line. The four square-shaped radiation patches are implemented on the $50 \mu \mathrm{m}$ top-polyimide substrate, and the feed line is realized on the $50 \mu \mathrm{m}$ bottom-polyimide layer by designing the simple square microstrip lines, which are all connected to each other and then excited by waveguide port. The ground plane including a coupling square slot has sandwiched between the top- and bottom-polyimide layers. The coupling square slot etched on the ground plane is exactly placed under the patch to optimum transfer the electromagnetic signal from the bottom feed line to the top radiation patch. To achieve high performance parameters without increasing the antenna's physical dimensions, the metamaterial and substrate integrated waveguide properties have been applied to the antenna structure by implementing linear tapered slots on the patch top surfaces and metallic via holes throughout the middle ground plane connecting top and bottom substrates to each other. The slots play the role of series left-handed (LH) capacitors $\left(C_{\mathrm{L}}\right)$ and the via holes act as shunt $\mathrm{LH}$ inductors $\left(L_{\mathrm{L}}\right)$. The overall dimension of the proposed metamaterial-based onchip antenna is $1000 \times 1000 \times 100 \mu \mathrm{m}^{3}$. This antenna can cover the frequency band from $0.6 \mathrm{THz}$ to $0.622 \mathrm{THz}$, which is equal to $20 \mathrm{GHz}$ bandwidth. The radiation gain and efficiency across the operating frequency band varies from $1.1 \mathrm{dBi}$ to $1.8 \mathrm{dBi}$, and from $58 \%$ to $60.5 \%$, respectively. The results confirm that the proposed on-chip antenna with compact dimensions, wide bandwidth over the terahertz domain, low profile, cost effective, simple configuration, and easy to manufacture can be potentially appropriate for terahertz integrated circuits.
\end{abstract}

\section{Introduction}

The millimeter-wave $(\mathrm{mmW})$ and terahertz $(\mathrm{THz})$ systems are being utilized for radio astronomy and imaging applications. Enhancing the requests for low-cost circuits and more data transfer at these bands has caused potential commercial applications such as automotive radars and high data rate systems [1-4]. These bands are attractive since with the reducing wavelengths the components physical size can be decreased, so in a specific physical area denser arrays can be constructed.
These applications become practical only if the solutions can be effective and highly integrated and at low cost [5-7].

In addition to the size decrement benefit, moving toward higher bands brings new tasks. Lossy silicon layers are not pleasantly suitable for realizing effective antennas, and for the devices operating over the microwave band, the antenna sizes make them the largest elements of the system that create them infeasible to produce on-chip. Antennas can operate effectively on low-loss printed circuit boards (PCB) that need interconnects between the antenna and the chips. 
Although, as the frequency moves higher, the matching networks and interconnects become lossier. Bond-wire interconnects restrict the functionality as they decrease the frequency band because of parasitic reactance. An alternative, flip-chip bonding enhances the cost. Hence, possible low-cost on-chip antenna solutions are of great interest $[8,9]$.

On-chip antennas enable system-on-chip (SoC) solutions, omitting the demand for conventional $50-\mathrm{ohm}$ interfaces and lossy RF interconnects [10]. Although, on-chip antennas present major difficulties because of physical constraints, low resistivity $(10 \Omega \cdot \mathrm{cm})$ silicon, that is, the typical layer of commercial integrated circuit processes forbids the effective antenna implementation. As well as, a considerable amount of power is coupled to the surfacewave modes on silicon substrates $[11,12]$. Although, typical integrated circuit processes enable an oxide layer thickness of $\sim 10 \mu \mathrm{m}$ that is still not sufficient in mm-W and $\mathrm{THz}$ bands, off-chip radiator and lens based solutions have been introduced in [13-15]. Off-chip radiators need postmanufacture steps on other layers, and lenses are bulky in comparison with the size of the chips. Utilizing high-permittivity superstrates provides a solution without the demand of additional manufacture steps and still achieves high efficiency on-chip antennas [16]. The main drawback of this method is the complexity of the design process and not applicable for mass production in a cost-effective method. Additionally, the on-chip antennas are operating on a narrow bandwidth.

Therefore, in this paper an on-chip antenna has proposed which is implemented on $50 \mu \mathrm{m}$ polyimide layers. The antenna structure has constructed from five stacked layers of two polyimide substrates and three aluminum layers as radiation patches, middle ground plane, and bottom feed line. The radiating patches have been isolated from the lossy polyimide by a ground plane, which eliminates the polyimide loss effect and causes the antenna to have a very thin substrate degrading the frequency bandwidth, radiation gain, and efficiency, which also makes the antenna unidirectional. The antenna excited by a microstrip feed line was placed on the bottom polyimide layer through coupling the electromagnetic signals to the top radiation patch through the coupling slot etched on the sandwiched ground plane realized between the two top- and bottom-polyimide substrates. The metallic via-hole-inspired substrate integrated waveguides (SIW) are also implemented to connect both polyimide layers to each other to reduce their losses and suppress the surface waves. Additionally, the metamaterial (MTM) property has employed to the radiation patches to extend their effective aperture area to improve the performance parameters. It is shown, after applying both SIW and MTM approaches, the on-chip antenna with simple design structure and compact dimensions exhibits wide bandwidth over terahertz $(\mathrm{THz})$ territory, high radiation gain, and efficiency over the operating bandwidth. The design process of the proposed on-chip antenna has been presented and investigated in Section 2. The results confirm that the proposed on-chip antenna can be applicable for integration in $\mathrm{THz}$ circuits.

\section{Design Process of the $50 \mu \mathrm{m}$ Polyimide Layer- Based On-Chip Antenna Design-Inspired MTM and SIW Properties for THz-Integrated Circuit Applications}

The configuration of the proposed on-chip antenna has been shown in Figure 1. The proposed antenna has constructed of five stacked layers of aluminum (radiation patches)-polyimide substrate aluminum (sandwiched ground plane)-polyimide substrate aluminum (microstrip feed line). The thickness, dielectric constant, and tangent loss of the polyimide substrates are $50 \mu \mathrm{m}, 3.5$, and 0.0027 , respectively. As it is obvious from Figure 1(a), on the top polyimide layer, four radiation patches with square shape have modeled, which all have been connected to each other by simple linear microstrip lines, since the antenna is excited only by one waveguide port. Underneath of the top polyimide substrate, the antenna's ground plane (GND) has been implemented, as shown in Figure 1(b). By realizing this GND layer, the antenna structure can be isolated from the lossy polyimide layer, which causes to improve the radiation properties and impedance matching of the antenna. Besides that, a square slot has been etched inside the GND layer as a coupling slot to transfer the electromagnetic (EM) energy to the top radiation patches. This slot is exactly aligned under the radiation patch to couple the optimum EM signal for the radiation process. The GND layer from its bottom side has been connected to the second polyimide layer as the bottom substrate with the same specifications with the top polyimide substrate. As it is displayed in Figure 1(c), underneath the bottom-polyimide substrate, a simple microstrip line is realized as the feeding line that, from its one side, has connected to the waveguide port to excite the structure. The schematic view of the proposed structure is shown in Figure 1(d), which clearly explains that this feeding line is exactly placed underneath the coupling slot etched inside the GND to transfer the maximum EM signal to the coupling slot, and consequently coupling the maximum EM signal from the GND's slot to the radiation patches on the top side of the top polyimide substrate to have optimum signal radiation. To suppress the substrate losses and diminish the surface waves, the SIW concept has been applied by implementing metallic via holes on the edges of the structure throughout the GND layer connecting both top- and bottom- 


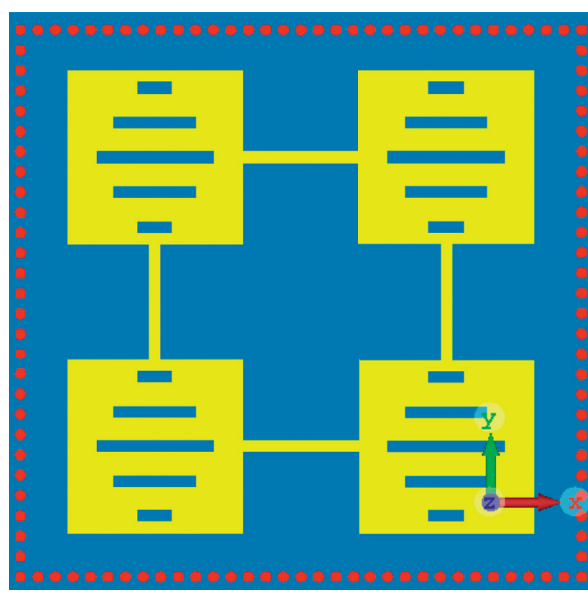

(a)

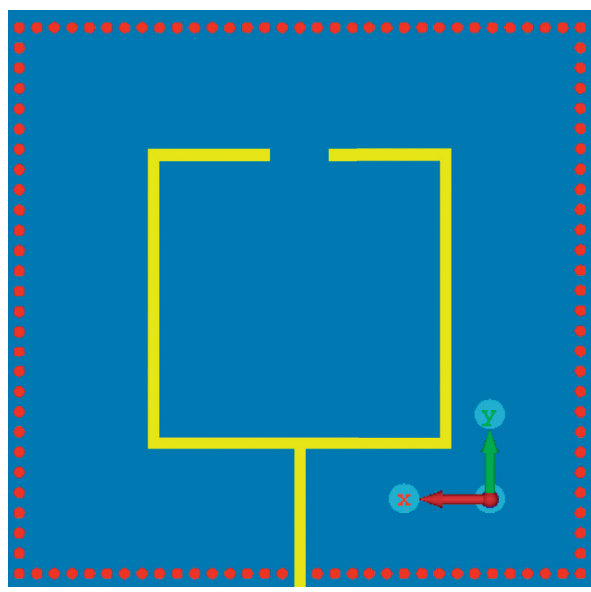

(c)

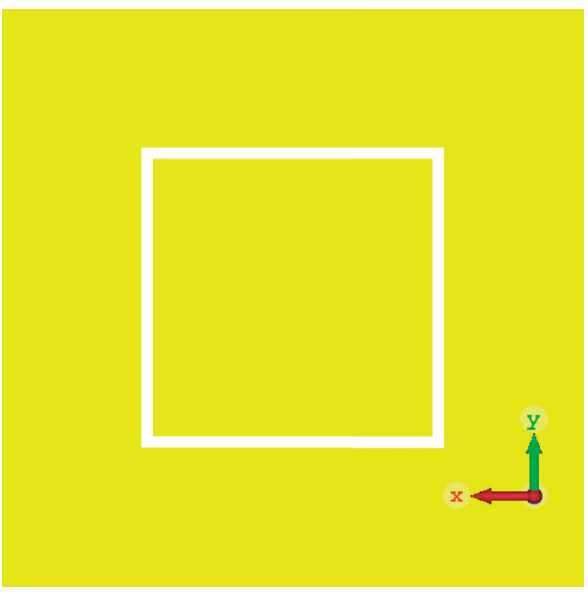

(b)

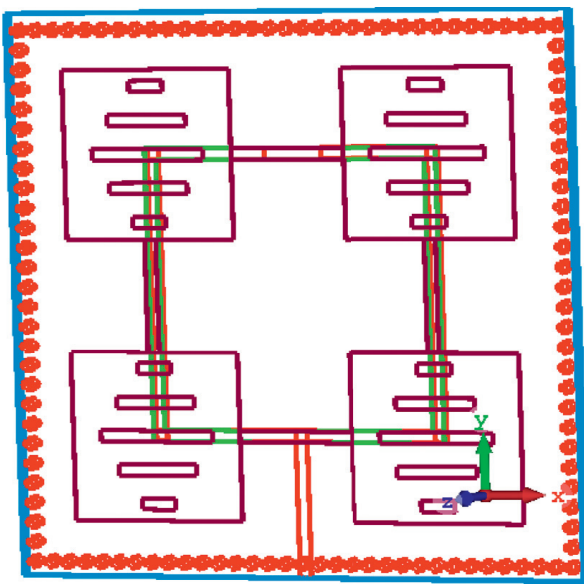

(d)

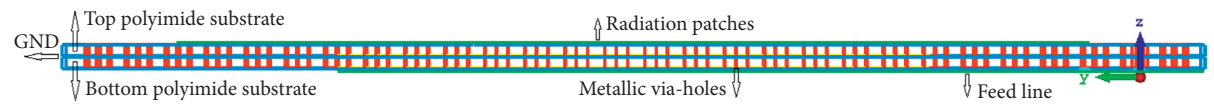

(e)

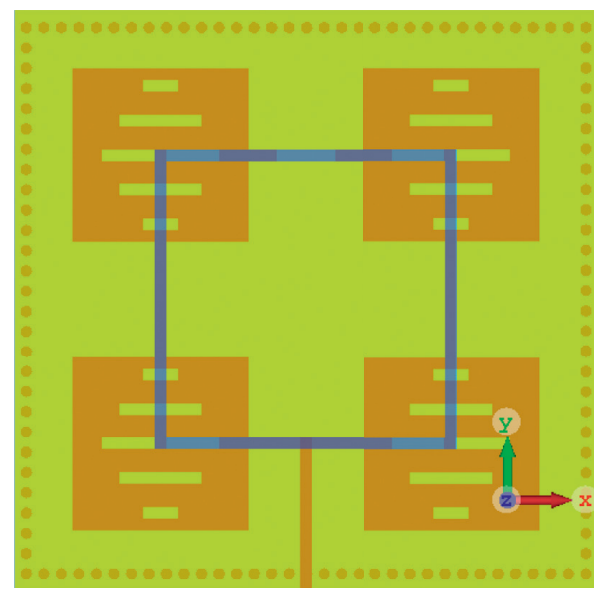

(f)

Figure 1: SIW- and MTM-based on-chip antenna configuration. (a) Top view, (b) middle GND, (c) back view, (d) schematic view, (e) side view, and (f) overall view to show all components realized on the top, middle, and bottom layers. 
polyimide layers to each other, as shown in Figure 1(e). This technique has been applied to the antenna structure with keeping constant physical dimensions. Figure 1(e) exhibits a side view of the five layers stacked on-chip antenna, on which all layers are connected to each other by the metallic via-hole-inspired SIW content. The reductions in the substrate losses and surface waves will cause to improve the performance parameters such as impedance matching, frequency bandwidth, gain, and radiation efficiency. Figure 1(f) displays the GND layer with its coupling slot which is sandwiched between the top- and bottom-polyimide substrates along with an overall view of the antenna structure showing all structural parameters such as radiation patches on the top-polyimide substrate, the microstrip lines connecting the patches to each others, the microstrip feed line on the bottom-polyimide layer, and metallic via-holes throughout the GND layers connecting both polyimide substrates to each other.

As shown in Figure 1, besides the SIW approach, the metamaterial (MTM) concept has been employed to the radiation patches to achieve more improvements on the performance parameters of the on-chip antenna, without extending its physical dimensions. In this method, the tapered slots have been engraved on the top surface of the square patches. Five linear slots have been etched on each patch which has expanded the effective aperture area of the patches without increasing their physical sizes, which will lead to increase in the radiation properties and extend in the frequency band.

The overall dimensions of the proposed on-chip antennainspired SIW and MTM properties is $1000 \times 1000 \times 100 \mu \mathrm{m}^{3}$, so its structural parameters have been listed in Table 1 . It is worth to comment that the proposed antenna has been modeled, tooled, and designed by the two 3D full-wave electromagnetic software of CST Microwave Studio and High-Frequency Structure Simulator (HFSS). To validate the antenna design process, the results achieved from both electromagnetic software have been presented and compared in Table 1, which show an excellent coherence with each other.

The reflection coefficient responses $\left(\mathrm{S}_{11}<-15 \mathrm{~dB}\right)$ of the proposed on-chip antenna based on the SIW and MTM approaches are plotted in Figure 2. To validate the results, Figure 2 shows the frequency bandwidths achieved from both CST and HFSS 3D full-wave EM simulators. It is shown that the on-chip antenna can cover the frequency band from $0.600 \mathrm{THz}$ to $0.622 \mathrm{THz}$, which is corresponding to a wide bandwidth of $22 \mathrm{GHz}$ and a fractional bandwidth of $3.6 \%$. Besides the impedance bandwidth, it is obvious that the proposed antenna applying SIW and MTM concepts shows an average impedance matching better than $25 \mathrm{~dB}$ across the entire frequency band. The S-parameter responses achieved from both EM simulators are listed in Table 2. It is shown that both CST and HFSS results have excellent agreement with each other, which confirm the effectiveness of the proposed approaches.

Besides the frequency bandwidth, the radiation specifications are other important parameters to design antenna structures. Figures 3 and 4 depict the radiation gain and efficiency curves over the operating frequency bandwidth. As it is shown in Figure 3, the radiation gains achieved by CST and HFSS software vary from $1.1 \mathrm{dBi}$ to $1.8 \mathrm{dBi}$ throughout the operating frequency band. The results from both simulators are summarized in Table 3 . It is exhibited that there is an excellent coherence between both CST and HFSS curves.

Figure 4 shows the radiation efficiency curves obtained by the CST and HFSS simulators over the frequency band. Both curves exhibit that the radiation efficiency changes from $58 \%$ to $60.5 \%$. The results from both simulators are presented in Table 4 . There is a good agreement between the CST and HFSS results.

The radiation patterns of the proposed on-antenna in the $x y$ - and $x z$-planes at $0.60 \mathrm{THz}, 0.61 \mathrm{THz}$, and $0.62 \mathrm{THz}$ are shown in Figure 5. The antenna's radiation energy is mainly focused in the $x$-direction. The beamwidth is narrower in the $x y$-plane. The radiation pattern is stable and symmetrical within the operating band of the antenna.

\section{Comparison Section}

In this section, the proposed on-chip antenna has been compared with other published papers available in the literature in terms of proposed approaches, dimensions, frequency band, gain, and radiation efficiency. The results are listed in Table 5. It is obvious that the proposed on-chip antenna with a compact dimension is operating over a much higher frequency band exhibiting comparable radiation gain and efficiency in comparison with other cited works in Table 5.

Therefore, the results confirm that the proposed on-chip antenna based on the MTM and SIW concepts with compact dimensions of $1 \times 1 \times 0.1 \mathrm{~mm}^{3}$ operating over $0.600 \mathrm{THz}$ to $0.622 \mathrm{THz}$ with the average gain and radiation efficiency of $1.5 \mathrm{dBi}$ and $60 \%$ can be good candidate for integration to utilize in $\mathrm{THz}$ circuits. Other advantages of the proposed antenna are its low profile, simple design, easy fabrication process, and low cost, which make it applicable for mass production. 
TABLE 1: Structural parameters of the proposed on-chip antenna-inspired SIW and MTM properties.

On-chip antenna dimensions

Ground plane

Radiation patches dimensions

Polyimide substrates thickness

Length variations of the slots etched on the patches

Width of the slots etched on the patches

Length of the lines connecting the patches

$1000 \times 1000 \times 100 \mu \mathrm{m}^{3}$

$1000 \times 1000 \mu \mathrm{m}^{2}$

$300 \times 300 \mu \mathrm{m}^{2}$

$50 \mu \mathrm{m}$

Width of the lines connecting the patches

$60 \mu \mathrm{m} \leq L \leq 200 \mu \mathrm{m}$

$20 \mu \mathrm{m}$

Radius of the metallic via-holes

Distance between the metallic via-holes

Length of each side of the square slot etched on the ground plane

$200 \mu \mathrm{m}$

$20 \mu \mathrm{m}$

$10 \mu \mathrm{m}$

$5 \mu \mathrm{m}$

$520 \mu \mathrm{m}$

Width of the square slot etched on the ground plane

$20 \mu \mathrm{m}$

Width of the feed line

$20 \mu \mathrm{m}$

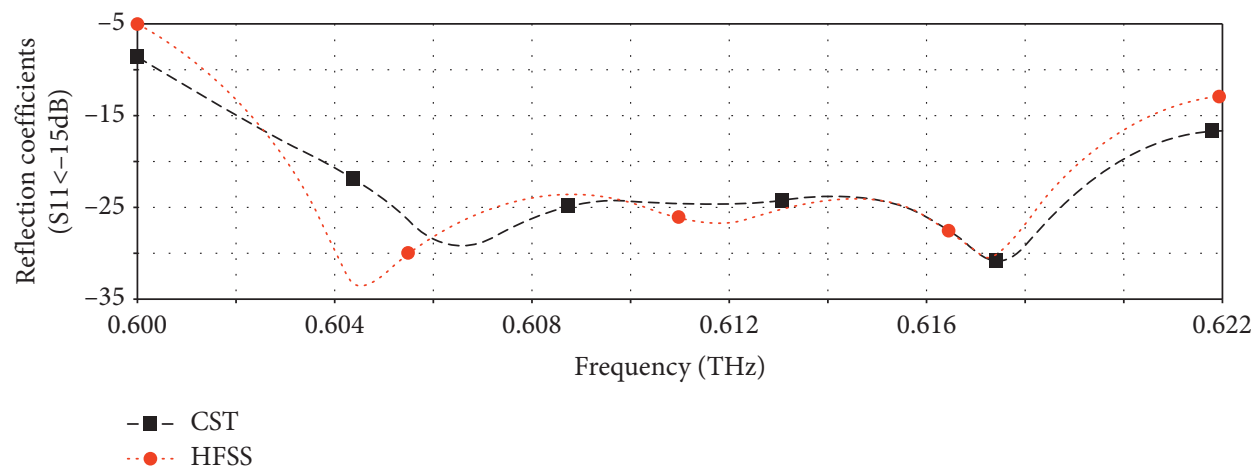

FIgURE 2: Reflection coefficient responses $\left(\mathrm{S}_{11}<-15 \mathrm{~dB}\right)$ achieved by the CST and HFSS EM simulators.

TABLE 2: S-parameter responses of the proposed antenna.

CST microwave studio

Frequency band

Bandwidth

$0.6-0.622 \mathrm{THz}$

$22 \mathrm{GHz}$

Fractional bandwidth

$3.6 \%$

Resonance frequencies

Impedance matching

and $f_{r 2}=617.5 \mathrm{GHz}$

HFSS

Frequency band

Bandwidth

$0.601-0.622 \mathrm{THz}$

$21 \mathrm{GHz}$

Fractional bandwidth

$3.43 \%$

Resonance frequencies

Impedance matching

$0.601-0.622 \mathrm{THz}$
$21 \mathrm{GHz}$
$3.43 \%$
$f_{r 1}=605 \mathrm{GHz}$ and $f_{r 2}=617.3 \mathrm{GHz}$
$25 \mathrm{~dB}$

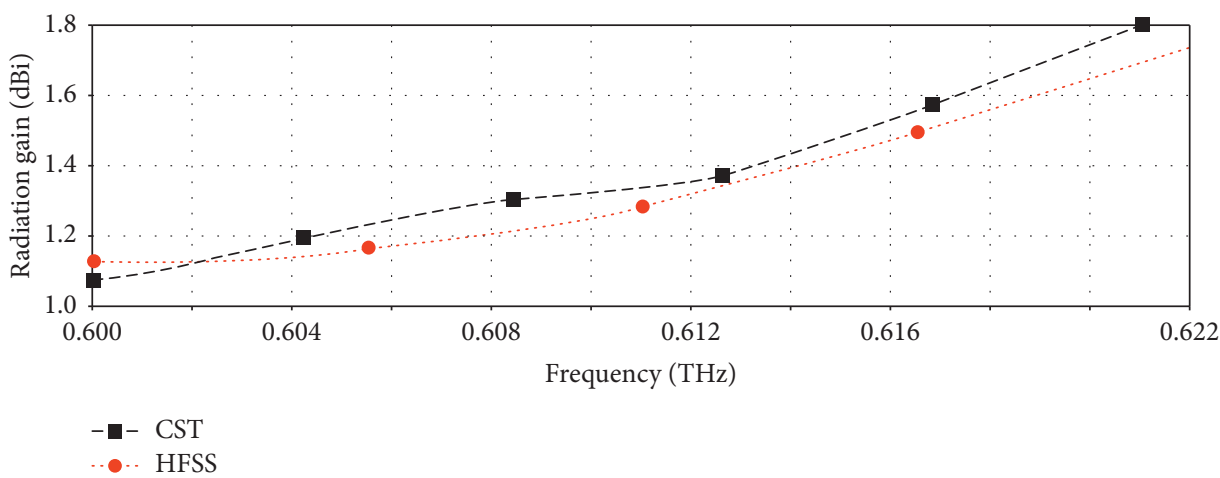

FIGURE 3: Radiation gain curves over the operating frequency band analyzed by the CST and HFSS EM simulators. 


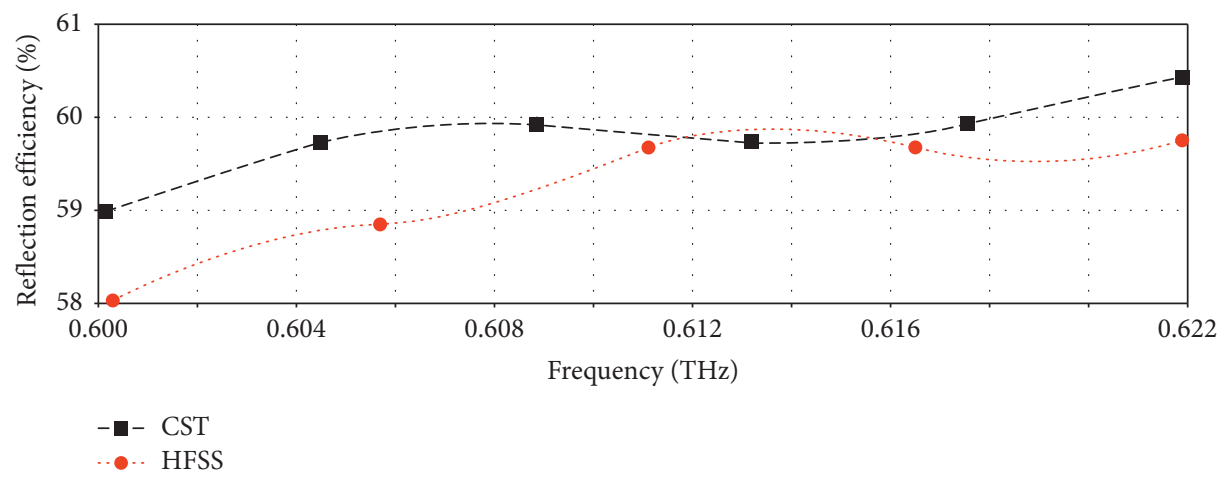

FIGURE 4: Radiation efficiency curves over the operating frequency band analyzed by the CST and HFSS EM simulators.

TABLE 3: Radiation gain specifications of the proposed antenna.

CST microwave studio

Minimum gain

$1.1 \mathrm{dBi}$

Maximum gain

$1.8 \mathrm{dBi}$

Average gain $1.4 \mathrm{dBi}$

HFSS

Minimum gain

$1.14 \mathrm{dBi}$

Maximum gain

$1.75 \mathrm{dBi}$

Average gain

$1.35 \mathrm{dBi}$

TABLE 4: Radiation efficiency specifications of the proposed antenna.

CST microwave studio

Minimum gain

Maximum gain

Average gain

$59.8 \%$

HFSS

Minimum gain

Average gain 


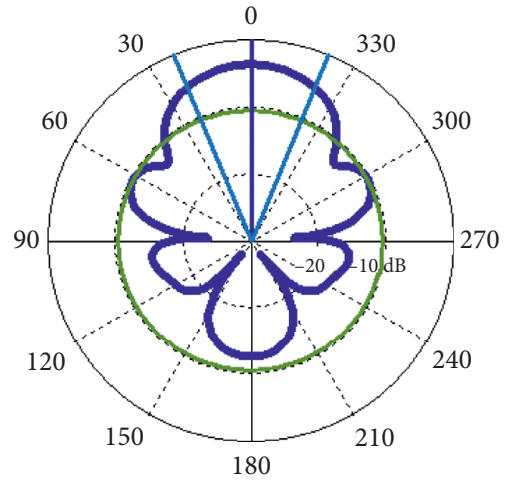

$0.60 \mathrm{THz}$

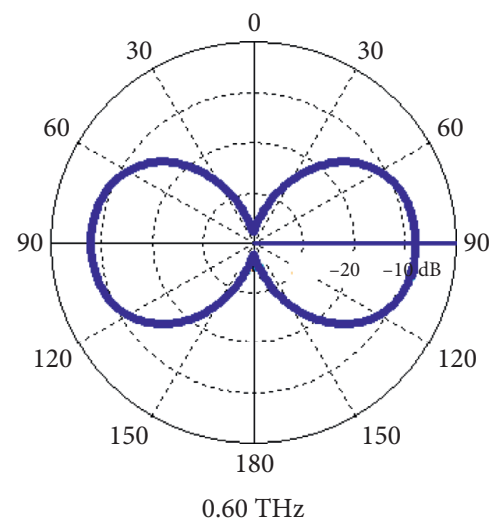

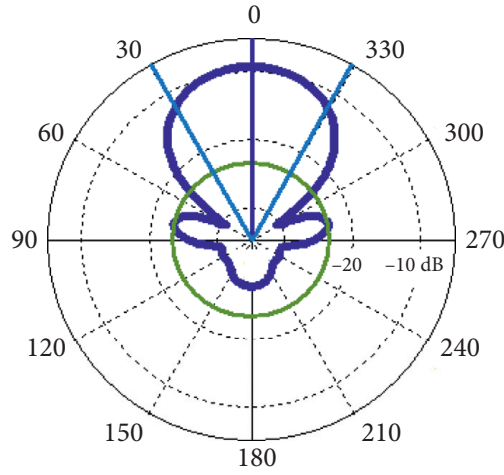

$0.61 \mathrm{THz}$

$x y$-plane

(a)

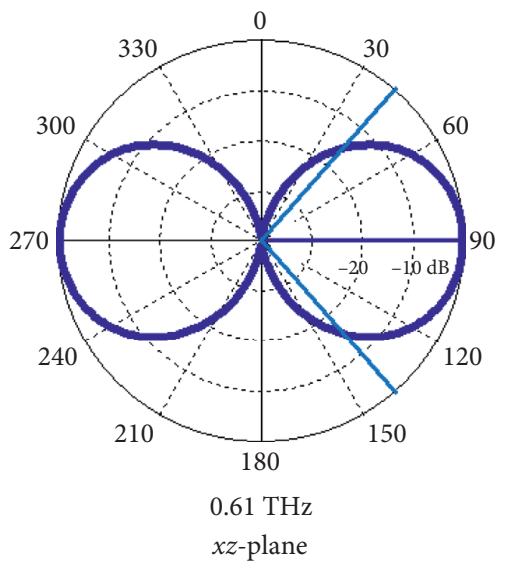

(b)

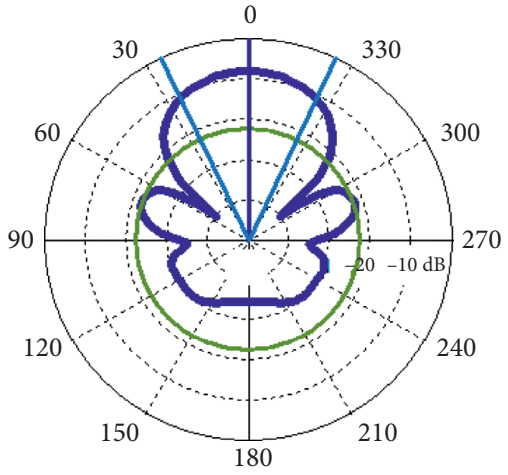

$0.62 \mathrm{THz}$

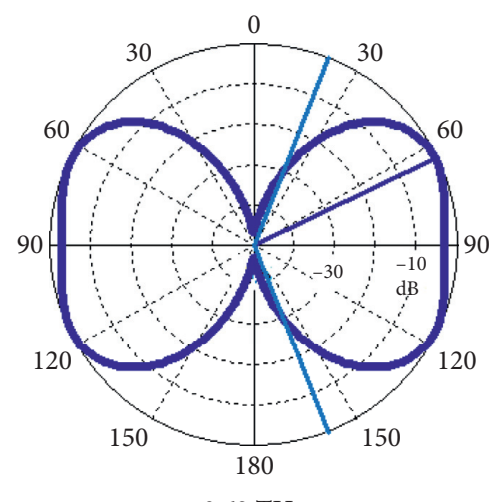

$0.62 \mathrm{THz}$

FigURE 5: Radiation patterns (normalized) of the antenna in the $x y$-plane and $x z$-plane at spot frequencies of $0.60 \mathrm{THz}, 0.61 \mathrm{THz}$, and $0.62 \mathrm{THz}$. (a) $x y$-plane $(0.60 \mathrm{THz}, 0.61 \mathrm{THz}$, and $0.62 \mathrm{THz})$. (b) $x z$-plane $(0.60 \mathrm{THz}, 0.61 \mathrm{THz}$, and $0.62 \mathrm{THz})$.

TABLE 5: State-of-the-art comparison.

\begin{tabular}{|c|c|c|c|c|c|}
\hline References & Antenna type & Bandwidth $(\mathrm{GHz})$ & $\begin{array}{l}\text { Gain } \\
(\mathrm{dBi})\end{array}$ & $\begin{array}{c}\text { Efficiency } \\
(\%)\end{array}$ & Size $\left(\mathrm{mm}^{3}\right)$ or $\left(\mathrm{mm}^{2}\right)$ \\
\hline$[4]-\mathrm{a}$ & OSAR antenna & $317-330$ & 1.4 & 41 & $0.5 \times 0.5$ \\
\hline$[4]-b$ & $1 \times 2$ antenna & $303-320$ & 4.1 & 38 & $0.5 \times 1$ \\
\hline [17] & Bowtie slot & $90-105$ & $\leq-1.78$ & - & $0.71 \times 0.31 \times 0.65$ \\
\hline$[18]$ & Differential-fed circularly polarized & $50-70$ & $\leq-3.2$ & - & $1.5 \times 1.5 \times 0.3$ \\
\hline [19] & Ring-shaped monopole & $50-70$ & $\leq 0.02$ & $\leq 35$ & - \\
\hline$[20]$ & Circular open loop & $57-67$ & $\leq-4.4$ & - & $1.8 \times 1.8 \times 0.3$ \\
\hline [21] & AMC-embedded squared slot antenna & $15-66$ & $\leq 2$ & - & $1.44 \times 1.1$ \\
\hline$[22]$ & Monopole & $45-70$ & $\leq 4.96$ & - & $1.9 \times 1.9 \times 0.25$ \\
\hline$[23]$ & Loop antenna & $65-69$ & $\leq 8$ & $\leq 96$ & $0.7 \times 1.25$ \\
\hline$[24]$ & Dipole antenna & $95-102$ & $\leq 4.8$ & - & - \\
\hline$[25]$ & Tab monopole & $45-75$ & $\leq 0.1$ & $\leq 42$ & $1.5 \times 1$ \\
\hline$[26]$ & Patch antenna & $\begin{array}{l}340 \text { (working } \\
\text { frequency) }\end{array}$ & -5.5 & 6.5 & $0.194 \times 0.023$ \\
\hline [27] & Circular-polarized SIW antenna & $251-283$ & -0.5 & 21.41 & $0.99 \times 0.99$ \\
\hline$[28]$ & SIW slot antenna & $\begin{array}{l}410 \text { (working } \\
\text { frequency) }\end{array}$ & -0.5 & 49.8 & $0.2 \times 0.2$ \\
\hline [29] & Dipole loaded AMC & $200-281$ & 0 & 63 & $0.25 \times 0.41$ \\
\hline$[30]$ & DRA & $\begin{array}{l}340 \text { (working } \\
\text { frequency) }\end{array}$ & 10 & 80 & $0.7 \times 0.7 \times 0.73$ \\
\hline$[31]$ & $2 \times 2$ slot antenna array & $\begin{array}{l}320 \text { (working } \\
\text { frequency) }\end{array}$ & 7.9 & - & $0.86 \times 0.86$ \\
\hline$[32]$ & $\begin{array}{c}2 \times 2 \text { cavity-backed rectangular slot loop antenna } \\
\text { array }\end{array}$ & $\begin{array}{l}340 \text { (working } \\
\text { frequency) }\end{array}$ & 7.7 & 39 & $1.1 \times 1.1$ \\
\hline$[33]$ & $2 \times 2$ DRA array & $334-350$ & 8.65 & 54 & $1.1 \times 1.5 \times 1.269$ \\
\hline This work & MTM and SIW & $600-622$ & $\geq 1$ & $\geq 58$ & $1 \times 1 \times 0.1$ \\
\hline
\end{tabular}




\section{Conclusion}

In this paper, the design process of a $50 \mu \mathrm{m}$ polyimide layer based on-chip antenna has been proposed and demonstrated, which is working over the higher frequency band of terahertz area from $0.600 \mathrm{THz}$ to $0.622 \mathrm{THz}$. The proposed structure has been constructed of five stacked layers. It has been excited by a simple coupling feeding mechanism, which is based on the transferring the EM signal from the bottom layer to the top layer throughout the middle GND layer having a coupling slot. To improve the performance parameters of the antenna, the feasible approaches based on the metamaterial (MTM) and substrate-integrated waveguide (SIW) concepts have been employed by realizing the tapered slots on the radiation patches and metallic via-holes on the edges of the structure throughout the GND layer connecting top- and bottom-polyimide substrates to each other, without increasing the physical dimensions of the structure. The proposed on-chip antenna with dimensions of $1000 \times 1000 \times 100 \mu \mathrm{m}^{3}$ can operate over a wide frequency range of $0.600 \mathrm{THz}$ to $0.622 \mathrm{THz}$, which is related to $22 \mathrm{GHz}$. Across the entire frequency band, the antenna has an average gain and efficiency of $1.5 \mathrm{dBi}$ and $60 \%$, respectively. The results affirm that the proposed antenna with low profile, simple design process, and cost effective can be applicable to use in $\mathrm{THz}$ integrated circuits.

\section{Data Availability}

The data used to support the findings of this study are available in the manuscript and from the corresponding author upon request.

\section{Conflicts of Interest}

The author declares no conflicts of interest.

\section{References}

[1] Y. He, Y. Chen, L. Zhang, S.-W. Wong, and Z. N. Chen, “An overview of terahertz antennas," China Communications, vol. 17, no. 7, pp. 124-165, 2020.

[2] N. Buadana, S. Jameson, and E. Socher, "A multiport chipscale dielectric resonator antenna for CMOS $\mathrm{THz}$ transmitters," IEEE Transactions on Microwave Theory and Techniques, vol. 68, no. 9, pp. 3621-3632, 2020.

[3] M. M. Honari, P. Mousavi, and K. Sarabandi, "Miniaturizedelement frequency selective surface metamaterials: a solution to enhance radiation of RFICs," IEEE Transactions on Antennas and Propagation, vol. 68, no. 3, pp. 1962-1972, 2020.

[4] H. Zhu, X. Li, Z. Qi, and J. Xiao, "A $320 \mathrm{GHz}$ octagonal shorted annular ring on-chip antenna array," IEEE Access, vol. 8, pp. 84282-84289, 2020.

[5] Ozan Dogan Gurbuz, High-Efficiency On-Chip Antennas for $\mathrm{Mm}$-Wave and $\mathrm{THz}$ Frequencies and Tunable RF MEMS Circuits for Wireless Communications, Ph.D. dissertation, UC San Diego Electronic Theses and Dissertations, San Diego, CA, USA, 2015.

[6] M. Alibakhshikenari, B. S. Virdee, L. Azpilicueta et al., "A comprehensive survey of metamaterial transmission-line based antennas: design, challenges, and applications," IEEE Access, vol. 8, pp. 144778-144808, 2020.

[7] E. Limiti, "High-gain on-chip antenna design on silicon layer with aperture excitation for terahertz applications," IEEE Antennas and Wireless Propagation Letters, vol. 19, no. 9, pp. 1576-1580, 2020.

[8] H. M. Cheema and A. Shamim, "The last barrier: on-chip antennas," IEEE Microwave Magazine, vol. 14, no. 1, pp. 79-91, 2013.

[9] B. S. Virdee, "Study on improvement of the performance parameters of a novel $0.41-0.47 \mathrm{THz}$ on-chip antenna based on metasurface concept realized on $50 \mu \mathrm{m}$ GaAs-layer," Scientific Reports, vol. 10, p. 11034, 2020.

[10] A. Mohammad, S. V. Bal, H. S. Chan, R. A. Abd-Alhameed, F. Francisco, and L. Ernesto, "High-ain Metasurface in Polyimide On-hip Antenna Based on CRLH-L for Sub Terahertz Integrated Circuits", Scientific Reports, vol. 10, p. 4298, 2020.

[11] A. Babakhani, X. Guan, A. Komijani, A. Natarajan, and A. Hajimiri, "A 77-ghz phased-array transceiver with on-chip antennas in silicon: receiver and antennas," IEEE Journal of Solid-State Circuits, vol. 41, no. 12, pp. 2795-2806, 2006.

[12] J. Edwards and G. Rebeiz, "High-efficiency silicon rfic millimeter-wave elliptical slot-antenna with a quartz lens," in Proceedings of the IEEE AP-S/URSI International Symposium on Antennas and Propagation, pp. 899-902, Boston, MA, July 2011.

[13] R. Alhalabi and G. Rebeiz, "Design of high-efficiency millimeter-wave microstrip antennas for silicon rfic applications," in Proceedings of the IEEE AP-S/URSI International Symposium on Antennas and Propagation, pp. 2055-2058, Boston, MA, July 2011.

[14] Y.-C. Ou and G. M. Rebeiz, "Differential microstrip and slotring antennas for millimeter-wave silicon systems," IEEE Transactions on Antennas and Propagation, vol. 60, no. 6, pp. 2611-2619, 2012.

[15] Y. C. Ou and G. M. Rebeiz, "On-chip slot-ring and high-gain horn antennas for millimeter-wave wafer-scale silicon systems," IEEE Transactions on Microwave Theory and Techniques, vol. 59, no. 8, pp. 1963-1972, 2011.

[16] J. M. Edwards and G. M. Rebeiz, "High-efficiency elliptical slot antennas with quartz superstrates for silicon rfics," IEEE Transactions on Antennas and Propagation, vol. 60, no. 11, pp. 5010-5020, 2012.

[17] M. S. Khan, F. A. Tahir, and H. M. Cheema, "Design of bowtie-slot on-chip antenna backed with E-shaped FSS at 94 $\mathrm{GHz}$," in Proceedings of the 10th European Conference on Antennas and Propagation (EuCAP), Davos, Switzerland, April 2016.

[18] L. Wang and W. Z. Sun, “A 60-GHz differential-fed circularly polarized on-chip antenna based on $0.18-\mu \mathrm{m}$ COMS technology with AMC structure," in Proceedings of the IET International Radar Conference, pp. 1-4, Hangzhou, China, October 2015.

[19] H. T. Huang et al., "A circular ring-shape monopole on-chip antenna with artificial magnetic conductor," IEEE APMC, vol. 1-3, 2015.

[20] X.-Y. Bao, Y.-X. Guo, and Y.-Z. Xiong, "60-GHz AMC-based circularly polarized on-chip antenna using standard 0.18 $\$$ \mu\$m CMOS technology," IEEE Transactions on Antennas and Propagation, vol. 60, no. 5, pp. 2234-2241, 2012.

[21] F. Lin and B. L. Ooi, "Integrated Millimeter-Wave On-Chip Antenna Design Employing Artificial Magnetic Conductor," in Proceedings of the IEEE International Symposium on RadioFrequency, pp. 174-177, Singapore, 2009. 
[22] S. Upadhyay and S. Srivastava, "A 60-GHz on-chip monopole antenna using silicon technology," IEEE AEMC, vol. 1-2, 2013.

[23] Y. Song et al., "The design of a high gain on-chip antenna for SoC application," in Proceedings of the IEEE MTT-S International Microwave Workshop Series on Advanced Materials and Processes for RF and THz Applications (IMWS-AMP), Suzhou, China, July 2015.

[24] M. Nafe, "Gain enhancement of low profile on-chip dipole antenna via Artificial Magnetic Conductor at $94 \mathrm{GHz}$," IEEE Antennas and Wireless Propagation Letters, vol. 16, pp. 2844-2847, 2015.

[25] W. Yang, K. Ma, K. S. Yeo, and W. M. Lim, “A 60GHz on-chip antenna in standard CMOS silicon Technology," in Proceedings of the 2012 IEEE Asia Pacific Conference on Circuits and Systems, pp. 252-255, Kaohsiung, Taiwan, 2012.

[26] C.-H. Li, C.-L. Ko, M.-C. Kuo, and D.-C. Chang, "A 340-GHz heterodyne receiver front end in 40-nm CMOS for $\mathrm{THz}$ biomedical imaging applications," IEEE Transactions on Terahertz Science and Technology, vol. 6, no. 4, pp. 625-636, 2016.

[27] Y. Shang, H. Yu, H. Fu, and W. M. Lim, “A 239-281 GHz CMOS receiver with on-chip circular-polarized substrate integrated waveguide antenna for sub-terahertz imaging," IEEE Transactions on Terahertz Science and Technology, vol. 4, no. 6, pp. 686-695, 2014.

[28] S. Hu, Y.-Z. Xiong, B. Zhang et al., "A SiGe BiCMOS transmitter/receiver chipset with on-chip SIW antennas for terahertz applications," IEEE Journal of Solid-State Circuits, vol. 47, no. 11, pp. 2654-2664, 2012.

[29] M. Nafe, A. Syed, and A. Shamim, "Gain-enhanced on-chip folded dipole antenna utilizing artificial magnetic conductor at $94 \mathrm{GHz}$," IEEE Antennas and Wireless Propagation Letters, vol. 16, pp. 2844-2847, 2017.

[30] X.-D. Deng, Y. Li, C. Liu, W. Wu, and Y.-Z. Xiong, “340 GHz on-chip 3-D antenna with $10 \mathrm{dBi}$ gain and $80 \%$ radiation efficiency," IEEE Transactions on Terahertz Science and Technology, vol. 5, no. 4, pp. 619-627, 2015.

[31] Z. J. Hou, Y. Yang, X. Zhu, S. Liao, S. K. Man, and Q. Xue, "A $320 \mathrm{GHz}$ on-chip slot antenna array using CBCPW feeding network in 0.13- $\mu \mathrm{m}$ SiGe technology," in Proceedings of the IEEE MTT-S Int. Microw. Symp. Dig., pp. 843-846, Honolulu, Hawaii, USA, June 2017.

[32] X.-D. Deng, Y. Li, W. Wu, and Y.-Z. Xiong, “340-GHz SIW cavity-backed magnetic rectangular slot loop antennas and arrays in silicon technology," IEEE Transactions on Antennas and Propagation, vol. 63, no. 12, pp. 5272-5279, 2015.

[33] C.-H. Li and T.-Y. Chiu, "Single flip-chip packaged dielectric resonator antenna for CMOS terahertz antenna array gain enhancement," IEEE Access, vol. 7, pp. 7737-7746, 2019. 